УДК $504.06+547.9$

\title{
Properties of Porous Carbon Materials Obtained by Alkaline Activation of Thermally Modified Aspen Wood
}

\author{
Nadezhda M. Mikova a, Ivan P. Ivanova, \\ Nikolai V. Chesnokov ${ }^{\mathrm{a}, \mathrm{b}}$ and Boris N. Kuznetsov ${ }^{\mathrm{a}, \overline{6} \mathrm{a}}$ \\ ${ }^{a}$ Institute of Chemistry and Chemical Technology SB RAS \\ 50/24 Akademgorodok, Krasnoyarsk, 660036, Russia \\ ${ }^{b}$ Siberian Federal University \\ 79 Svobodny, Krasnoyarsk, 660041, Russia
}

Received 16.11.2015, received in revised form 20.12.2014, accepted 12.01.2015

The influence of thermal pretreatment of aspen wood at conditions of pyrolysis and explosive autohydrolysis on the texture and adsorption properties of porous carbon materials (PCM), obtained by alkaline activation of modified samples, was studied. Preliminary pyrolysis of wood at $300-400{ }^{\circ} \mathrm{C}$ promotes the development of porous structure of PCM in the higher degree as compared to explosive autohydrolysis at $170-200^{\circ} \mathrm{C}$. At optimal conditions of pyrolysis and alkaline activation processes it is possible to obtain PCM with specific surface area about $3000 \mathrm{~m}^{2} / \mathrm{g}$.

Keywords: aspen wood, modification, pyrolysis, explosive autohydrolysis, alkaline activation, porous carbon, properties.

(C) Siberian Federal University. All rights reserved

* Corresponding author E-mail address: bnk@icct.ru 


\title{
Свойства пористых углеродных материалов, полученных щелочной активацией термически модифицированной древесины осины
}

\author{
Н.М. Микова ${ }^{a}$, И.П. Иванов ${ }^{\text {, }}$ \\ Н.В. Чесноков ${ }^{\mathrm{a}, \tilde{0}}$, Б.Н. Кузнецов ${ }^{\mathrm{a}, \boldsymbol{0}}$ \\ ${ }^{a}$ Институт химии и химической технологии СО РАН \\ Россия, 660036, Красноярск, Академгородок, 50/24 \\ ${ }^{6}$ Сибирский федеральныий университет \\ Россия, 660041, Красноярск, пр. Свободный, 79
}

Изучено влияние термической предобработки древесины осины в условиях пиролиза и взрывного автогидролиза на текстурные и адсорбиионные свойства пористых углеродных материалов (ПУМ), получаемых щелочной активацией модифицированных образцов. Предварительный пиролиз древесины при 300-400 ${ }^{\circ} \mathrm{C}$ в большей степени, чем автогидролиз при 170-200 ${ }^{\circ} \mathrm{C}$, способствует развитию пористой структуры ПУМ. При оптимальных условиях прочессов пиролиза и щелочной активации возможно получение ПУМ с удельной поверхностью около $3000 \mathrm{~m}^{2} / 2$.

Ключевые слова: древесина осины, модификачия, пиролиз, взрывной автогидролиз, щелочная активачия, пористый углерод, свойства.

\section{Введение}

В настоящее время актуальны исследования, направленные на совершенствование способов производства высокопористых углеродных материалов из доступных видов углеродсодержащего сырья, к числу которых относится древесная биомасса [1].

Древесное сырьё представляет собой лигноцеллюлозный полимер сложного состава и неоднородного строения, что затрудняет получение на его основе пористых углеродных материалов (ПУМ) с однородной пористой структурой при использовании традиционных методов активации $[2,3]$.

Задачу направленного формирования пористой структуры углеродных адсорбентов с учетом конкретных областей их применения решают путем подбора оптимальных условий активации сырья и использования различных методов его предобработки [4]. Варьируя методы предобработки (термические, химические, комбинированные), можно влиять на формирование пористой структуры и свойства получаемых ПУМ $[5,6]$.

Ранее было показано, что высокопористые углеродные материалы могут быть получены активацией углеродсодержащего сырья гидроксидами натрия и калия $[7,8]$. В современной литературе отсутствуют сведения о влиянии предварительных обработок древесного сырья на развитие пористой структуры углеродного продукта, получаемого при последующей термощелочной активации модифицированной древесины.

Целью данной работы являлось сопоставление закономерностей формирования пористой структуры углеродных материалов, получаемых щелочной активацией древесины осины, 
предварительно термически модифицированной в условиях пиролиза и взрывного автогидролиза перегретым паром.

\section{Экспериментальная часть}

В качестве исходного сырья использовали воздушно-сухие опилки древесины осины, фракция размером 1-2 мм. Состав древесины осины (вес. \%): целлюлоза - 46, гемицеллюлозы 24 , лигнин - 19,4, экстрактивные - 7,5, зольность - 0,3; зола содержит Сa 0,2 \%, $\mathrm{Mg}, \mathrm{Si}, \mathrm{S}, \mathrm{P}, \mathrm{Cu}$, $\mathrm{Fe}-0,1 \%$. Элементный состав образцов исходной древесины осины представлен в табл. 1.

Предварительный пиролиз древесных опилок проводили в интервале температур 300$700{ }^{\circ} \mathrm{C}$ и атмосфере аргона. Скорость подъема температуры составляла $20{ }^{\circ} \mathrm{C} / м и н$, выдержка при конечной температуре 0,5 ч.

Процесс взрывного автогидролиза (АГ) древесины осины осуществляли на установке, описанной в работе [9]. Древесное сырье подвергали кратковременному воздействию насыщенным водяным паром в интервале температур 170-200 ${ }^{\circ} \mathrm{C}$, давлений 2,5-4,0 МПа и продолжительности процесса $0,5-3$ мин. Образцы высушивали до постоянного веса в сушильном шкафу при температуре $105^{\circ} \mathrm{C}$.

Дальнейшую химическую активацию исходных, автогидролизованных и пиролизованных образцов древесины осины гидроксидами калия и натрия (при весовых соотношениях древесина: щелочь $1: 1$ - 1:4) осуществляли со скоростью подъема температуры $10^{\circ} \mathrm{C} /$ мин до $800{ }^{\circ} \mathrm{C}$ последующей изотермической выдержкой в течение 1 ч в атмосфере аргона.

Данные о текстурных и структурных характеристиках образцов углеродных материалов получены на приборе ASAP 2420 «Micrometrics» из изотерм адсорбции азота при 77 К в диапазоне относительных давлений $P / P o$ 0,005 - 0,995.

Элементный анализ образцов на C, H, N, S и О выполнен на приборе “Flasch-1000”.

\section{Результаты и обсуждение}

Изучено влияние содержания щелочи в смеси ДО/КОН на характеристики пористой структуры полученных углеродных материалов. Установлено, что с ростом соотношения ДО/КОН от 1:1 до 1:4 происходит увеличение удельной поверхности и общего объема пор полученных ПУМ от 848 до $1348 \mathrm{~m}^{2} / \Gamma$ и 0,40 до $0,70 \mathrm{~cm}^{3} / \Gamma$ соответственно (табл. 2). Таким образом, содержание КОН является решающим фактором развития пористой структуры углеродного продукта термощелочной активации древесины осины.

Из представленных в табл. 2 данных видно, что увеличение количества КОН приводит не только к росту общего объема пор, но и к повышению объема микропор, доля которых может достигать 50 \% от общего объема пор.

Таблица 1. Характеристика состава опилок древесины осины (ДО)

\begin{tabular}{|c|c|c|c|c|c|c|}
\hline \multirow{2}{*}{ Сырьё } & \multicolumn{5}{|c|}{ Элементный состав, daf, \% } & \multirow{2}{*}{ Зольность } \\
\cline { 2 - 6 } & $\mathrm{C}$ & $\mathrm{H}$ & $\mathrm{N}$ & $\mathrm{S}$ & $\mathrm{O}$ & \\
\hline ДО & 48,7 & 5,3 & 0 & $\leq 0,1$ & 38,6 & $\leq 0,3$ \\
\hline
\end{tabular}


Таблица 2. Влияние соотношения ДО/КОН на текстурные характеристики получаемых углеродных материалов

\begin{tabular}{|c|c|c|c|c|c|}
\hline $\begin{array}{c}\text { Номер } \\
\text { образца }\end{array}$ & $\begin{array}{c}\text { Соотношение } \\
\text { ДО/КОН }\end{array}$ & $\begin{array}{c}\mathrm{S}_{\text {Бэт, }} \\
\mathrm{M}^{2} / \Gamma\end{array}$ & $\begin{array}{c}\text { Общий объем } \\
\text { пор, } \mathrm{cm}^{3} / \Gamma\end{array}$ & $\begin{array}{c}\text { Объем } \\
\text { микропор, } \mathrm{cm}^{3} / \Gamma\end{array}$ & $\begin{array}{c}\text { Ширина пор } \\
\mathrm{D}, \mathrm{нм}\end{array}$ \\
\hline 1 & $1: 1$ & 848 & 0,40 & 0,17 & 1,97 \\
\hline 2 & $1: 2$ & 1005 & 0,50 & 0,23 & 2,14 \\
\hline 3 & $1: 3$ & 1100 & 0,53 & 0,27 & 2,20 \\
\hline 4 & $1: 4$ & 1348 & 0,70 & 0,35 & 2,25 \\
\hline
\end{tabular}

Условия термоактивации: скорость подъема температуры до $800^{\circ} \mathrm{C} 5{ }^{\circ} \mathrm{C} /$ мин, продолжительность выдержки в аргоне 1 ч.

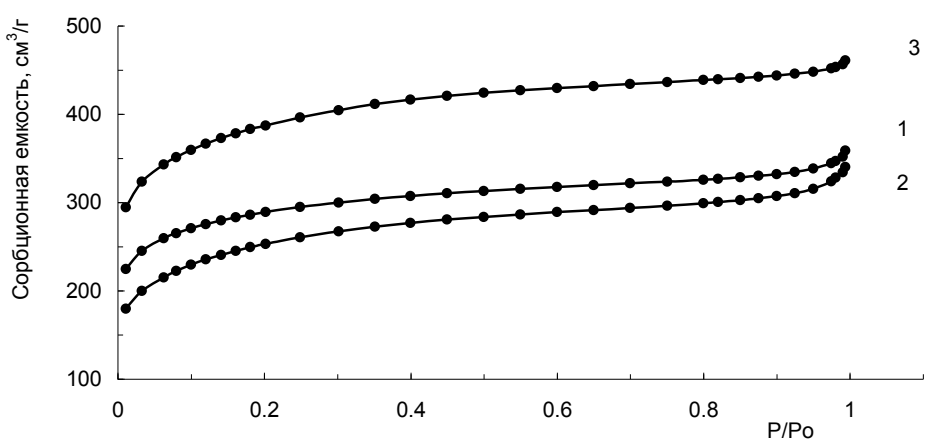

Рис. 1. Изотермы адсорбции азота на образцах ПУМ, полученных при соотношениях ДО/КОН, равных $1: 2(1), 1: 3(2), 1: 4(3)$

Изотермы адсорбции азота были использованы для расчета общего объема микропор с размером около 2 нм. Изотермы адсорбции $\mathrm{N}_{2}$ на образцах ПУМ, полученных термощелочной активацией ДО при $800{ }^{\circ} \mathrm{C}$ при различном соотношении ДО/КОН, представлены на рис. 1. В случае образца ПУМ, полученного при весовом соотношении ДО/КОН = 1:4 (кривая 3), наблюдается изотерма I типа с более крутым наклоном, чем для образцов, полученных при меньших соотношениях (кривые 1, 2). Для образцов, описываемых изотермами 2 и 3 , характерно более широкое распределение микропор по размерам со средним значением 2,2-2,25 нм.

Известно, что эффективность щелочной активации во многом зависит от химической природы и реакционной способности предшественника и условий его предварительной обработки [10-13].

Метод взрывного автогидролиза (АГ) был использован для частичной деструкции и механического разупорядочения древесины осины с целью воздействия на последующий процесс термощелочной активации автогидролизованной древесины осины (АДО).

Изучено влияние температуры, давления и продолжительности обработки древесины водяным паром в условиях взрывного автогидролиза на выход, текстурные характеристики и сорбционные свойства ПУМ, полученных термощелочной активацией АДО (табл. 3).

В результате проведенных исследований обнаружен сложный характер влияния режимных параметров процесса взрывного автогидролиза на выход, строение и сорбционные свой- 
Таблица 3. Выход и свойства ПУМ, полученных термощелочной активацией предварительно автогидролизованной древесины осины

\begin{tabular}{|l|l|c|c|c|}
\hline Образец & Условия автогидролиза & Выход ПУМ, \% & $\mathrm{S}_{\text {вэт, } \mathrm{M}^{2} / \Gamma}$ & $\mathrm{V}$ пор, $\mathrm{cm}^{3} / \Gamma$ \\
\hline АДО/КОН & $\mathrm{T}=200^{\circ} \mathrm{C}, \mathrm{P}=4,0 \mathrm{MPa}, 0,5 \mathrm{мин}$ & 6,5 & 1446 & 0,60 \\
\hline АДО/КОН & $\mathrm{T}=180^{\circ} \mathrm{C}, \mathrm{P}=3,0 \mathrm{MPa}, 3$ мин & 5,0 & 1200 & 0,50 \\
\hline АДО/КОН & $\mathrm{T}=170^{\circ} \mathrm{C}, \mathrm{P}=3,0 \mathrm{MPa}, 0,5$ мин & 7,2 & 1600 & 0,67 \\
\hline АДО, без КОН & $\mathrm{T}=180^{\circ} \mathrm{C}, \mathrm{P}=3,0 \mathrm{MPa}, 3$ мин & 15 & 12 & 0,001 \\
\hline
\end{tabular}

Условия термощелочной активации аналогичны приведенным в табл. 2.

ства углеродных продуктов. ПУМ, полученные из автогидролизованного при $170{ }^{\circ} \mathrm{C}$ образца, сохраняющего в неизмененном виде основные компоненты древесной биомассы - лигнин и целлюлозу [15], имеют более высокую удельную поверхность и объем пор, чем ПУМ из образцов, предварительно подвергнутых более жестким условиям обработки водяным паром.

Увеличение продолжительности паровой активации до 3 мин и повышение температуры процесса автогидролиза до $200{ }^{\circ} \mathrm{C}$ приводит к снижению удельной поверхности получаемых ПУМ с 1600 до 1200 м²/г. Вероятно, это происходит вследствие преобразования химического состава древесной биомассы за счет частичного гидролиза целлюлозы и деполимеризации лигнина [14], что снижает способность модифицированной древесины к формированию пористой углеродной структуры в ходе дальнейшей активации КОН.

Чем «мягче» условия взрывного автогидролиза: ниже температура, давление, время воздействия, тем выше выход, удельная поверхность и объем пор ПУМ, получаемых активированием КОН автогидролизованной древесины осины.

В отсутствие щелочного активатора процесс карбонизации АДО в аналогичных условиях приводит к образованию углеродного продукта с большим выходом (15-17 \% вес.), но со слабо развитой удельной поверхностью (12-18 м²/г).

Таким образом, обработанные паром образцы ДО с различной глубиной гидролитических превращений проявляют лучшую способность к развитию пористости под влиянием КОН, чем исходная древесина.

Изучено влияние предварительной термообработки в условиях пиролиза образцов ДО в атмосфере аргона при вариации температур в интервале $300-700{ }^{\circ} \mathrm{C}$ на свойства ПУМ, получаемых при последующей термощелочной активации пиролизованных образцов (табл. 4).

Активирующее действие КОН возрастает по мере совершенствования углеродной структуры образцов частично пиролизованной древесины и проявляется в увеличении значений

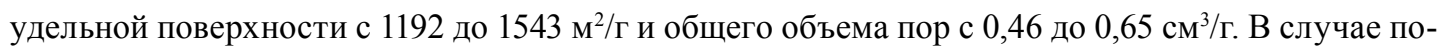
лучения ПУМ в аналогичных условиях из немодифицированной ДО максимально достижимая величина удельной поверхности не превышает 1350 м²/г, а общего объема пор - 0,70 cм³/г.

Активирующий эффект $\mathrm{NaOH}$, напротив, наиболее выражен по отношению к слабо пиролизованным образцам, в составе которых сохраняется больше исходных функциональных групп. В частности, воздействие $\mathrm{NaOH}$ на менее организованную углеродную матрицу пиролизованного при $300{ }^{\circ} \mathrm{C}$ образца (табл. 5) заключается в заметном увеличении удельной поверхности $\left(3040 \mathrm{~m}^{2} / \Gamma\right)$ и общего объема пор $\left(1,59 \mathrm{~cm}^{3} / \Gamma\right)$ полученных ПУМ. Повышение темпера- 
Таблица 4. Выход и свойства ПУМ, полученных термощелочной активацией образцов предварительно пиролизованной древесины осины (ПДО) при весовом соотношении ПДО/щелочь = 1:3

\begin{tabular}{|c|c|c|c|c|}
\hline Образец & Температура, ${ }^{\circ} \mathrm{C}$ & Выход ПУМ, \% & $\mathrm{S}_{\text {Бэт }}, \mathrm{M}^{2} / \Gamma$ & V пор, см$^{3} / \Gamma$ \\
\hline \multicolumn{5}{|c|}{ Активация КОН } \\
\hline \multirow{5}{*}{ ПДО/КОН } & 300 & 11,5 & 1192 & 0,46 \\
\hline & 400 & 22,7 & 1307 & 0,59 \\
\hline & 500 & 38,1 & 1543 & 0,65 \\
\hline & 600 & 54,4 & 1390 & 0,48 \\
\hline & 700 & 54,0 & 1090 & 0,43 \\
\hline \multicolumn{5}{|c|}{ Активация $\mathrm{NaOH}$} \\
\hline \multirow{5}{*}{ ПДО/NaOH } & 300 & 10,6 & 2550 & 1,16 \\
\hline & 400 & 23,5 & 2440 & 1,09 \\
\hline & 500 & 35,0 & 2317 & 1,07 \\
\hline & 600 & 43,1 & 1993 & 0,89 \\
\hline & 700 & 36,1 & 1780 & 0,86 \\
\hline
\end{tabular}

Условия термощелочной активации аналогичны приведенным в табл. 2.

Таблица 5. Влияние соотношения ПДО/ $\mathrm{NaOH}$ на свойства ПУМ, полученных термощелочной активацией ДО, предварительно пиролизованной при $300^{\circ} \mathrm{C}$

\begin{tabular}{|c|c|c|c|c|c|}
\hline ПДО/ $\mathrm{NaOH}$, & $\mathrm{S}_{\text {вэт }}, \mathrm{M}^{2} / \Gamma$ & $\mathrm{V}$ пор, $\mathrm{cm}^{3} / \Gamma$ & $\mathrm{S}$ микропор, $\mathrm{M}^{2} / \Gamma$ & $\mathrm{V}$ микропор, $\mathrm{cm}^{3} / \Gamma$ & $\mathrm{D}$ пор, нм \\
\hline $1: 3$ & 2550 & 1,16 & 1954 & 0,91 & 2,0 \\
\hline $1: 4$ & 3040 & 1,59 & 2658 & 1,25 & 2,2 \\
\hline
\end{tabular}

Условия термощелочной активации аналогичны приведенным в табл. 2.

туры предварительного пиролиза древесины до 500-700 ㄷ сопровождается последовательным снижением удельной поверхности и объема пор.

Изотермы адсорбции $\mathrm{N}_{2}$ на активированных образцах $\mathrm{NaOH}$ образцах ПдО принадлежат к I типу и являются общими для микропористых систем (рис. 2). Вид изотермы 1 указывает на большую пористость образца ПУМ, полученного активацией при соотношении ПДО/NaOH $=1: 4$, и на относительно широкий диапазон распределения пор по размерам. Причем увеличение концентрации щелочи приводит не только к росту общего объема пор, но и к увеличению объема микропор (табл. 5). Полученные ПУМ являются преимущественно микропористыми.

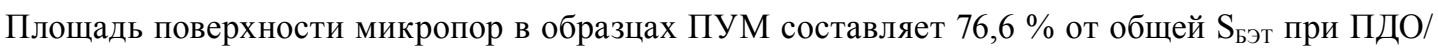
$\mathrm{NaOH}=1: 3$ и $87,4 \%-$ при ПДО/NaOH $=1: 4$.

Исходя из анализа полученных результатов, можно заключить, что предварительный пиролиз ДО в интервале температур 300-400 ㄷ благоприятствует в большей степени развитию удельной поверхности и объема пор в ходе последующей активации образцов КОН и $\mathrm{NaOH}$, чем более высокие температуры пиролиза или обработки паром в условиях взрывного автогидролиза. Вероятно, при этом процесс формирования пористой структуры ПУМ протекает в условиях, оптимально сочетающих достаточное число реакционноспособных функциональ- 


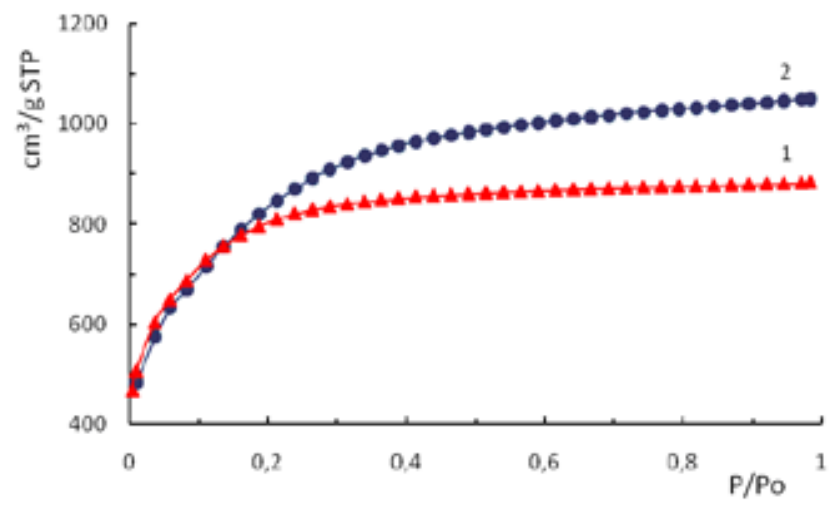

Рис. 2. Изотермы сорбции азота на образцах ПУМ, полученных при соотношениях ПДО/NaOH, paвных $1: 3$ (1) и $1: 4(2)$

ных групп на поверхности частично карбонизованного предшественника и концентрации активирующего агента [15].

При сопоставлении данных по сорбционной способности в отношении бензола ПУМ, полученных термощелочной активацией предварительно модифицированной ДО (табл. 2-4), определено, что максимальной сорбционной активностью отличаются образцы с наиболее высокой удельной поверхностью и объемом пор.

\section{Заключение}

В результате проведенных исследований установлено, что предварительный пиролиз ДО в интервале температур $300-700{ }^{\circ} \mathrm{C}$ способствует в большей степени формированию развитой пористой структуры углеродных материалов, образующихся в ходе последующей термоактивации $\mathrm{KOH}$ и $\mathrm{NaOH}$, чем предобработка ДО паром в условиях взрывного автогидролиза. Предварительный пиролиз древесины при $300-400{ }^{\circ} \mathrm{C}$ делает возможным получение высокопористых углеродных материалов с удельной поверхностью до $3000 \mathrm{~m}^{2} /$ и и развитой микропористостью (доля микропор $\leq 87 \%$ ), в то время как модифицирующая обработка взрывным автогидролизом не позволяет получать ПУМ с удельной поверхностью свыше $1600 \mathrm{~m}^{2} /$.

При этом оба способа термической модификации древесины осины способствуют формированию более развитой пористой структуры под влиянием щелочи по сравнению с древесиной, не подвергнутой предварительному активированию.

Выход ПУМ, полученных активацией гидроксидами калия и натрия пиролизованной древесины осины, увеличивается в 2-7 раз по сравнению с ПУМ, полученными из автогидролизованной или исходной ДО.

Таким образом, путем подбора режимов предварительной термохимической модификации древесины осины методами пиролиза и взрывного автогидролиза можно обеспечить в ходе последующей термохимической активации возможность регулирования пористой структуры и свойств получаемых ПУМ. 


\section{Список литературы}

1. Byrne C.E., Nagle D.C. Carbonization of wood for advanced material application // Carbon. 1997. Vol. 35. P. 267-273.

2. Sevilla M., Fuertes A.B. The production of carbon materials by hydrothermal carbonization of cellulose // Carbon. 2009. Vol. 42. P. 2281-2289.

3. Phan N.H., Rio S., Faur C., Coq L.L., Cloirec P.L., Nguyen T.H. Production of fibrous activated carbons from natural cellulose (jute, coconut) fibers for water treatment applications // Carbon. 2006. Vol. 44. P. 2569-2577.

4. Rodríguez-Reinoso F., Molina-Sabio M. Activated carbons from lignocellulosic materials by chemical and/or physical activation: an overview // Carbon. 1992. Vol. 30. P. 1111-1118.

5. Klijanienko A., Lorenc-Grabowska E., Gryglewicz G. Development of mesoporosity during phosphoric acid activation of wood in steam atmosphere // Bioresource Technology. 2008. Vol. 99. P. 7208-7214.

6. Schroder E., Thomausk K., Weber Ch., Hornung A., Tumiatti V. Experiments on the generation of activated carbon from biomass // J. Anal. Appl. Pyrolysis. 2007. Vol. 79. P. 106-111.

7. Diaz-Teran J., Nevskaia D.N., Fierro J.L.G., Lopez-Peinado A.J., Jerez A. Study of chemical activation process of a lignocellulosic material with KOH by XPS and XRD // Microporous and Mesoporous Materials. 2003. Vol. 60. P. 173-181.

8. Lillo-Ro'denas MA, Marco-Lozar JP, Cazorla-Amoro's D,Linares-Solano A. Activated carbons prepared by pyrolysis of mixtures of carbon precursor/alkaline hydroxide // J Anal Appl. Pyrolysis 2007. Vol. 80. P.166-74.

9. Kuznetsov B.N., Efremov A.A., Levdanskii V.A., Kuznetsova S.A., Polezhaeva N.I., Shilkina T.A. and Krotova I.V. The using of non-isobaric pre-hydrolysis for the isolation of organic compounds from wood and bark // Bioresourse Technology. 1996. Vol. 58. P. 181-188.

10. Mamleev V., Bourbigot S., Yvon J. Kinetic analysis of the thermal decomposition of cellulose: The main step of mass loss // J. Anal. Appl. Pyrolysis. 2007. Vol. 80. P. 151-165.

11. Muller-Hagedorn M., Bockhorn H.. Pyrolytic behaviour of different biomasses (angiosperms) (maize plants, straws, and wood) in low temperature pyrolysis // J. Anal. Appl. Pyrolysis. 2007. Vol. 79. P. $136-146$.

12. Evans M.J., Halliop E., MacDonald J.A.F. The production of chemically-activated carbon // Carbon. 1999. Vol. 37. P. 269-274.

13. Luik H., Johannes I., Palu V., Luik L., Krwusement K. Transformation of biomass internal oxygen at varied pyrolysis conditions // J. Anal. Appl. Pyrolysis. 2004. Vol. 79. P. 121-127.

14. Кузнецова С.А., Александрова Н.Б., Кузнецов Б.Н. Состав и превращения основных компонентов автогидролизованной древесины сосны, ели и осины // Химия в интересах устойчивого развития. 2001. T. 9(5). C. 655-665. [Kuznetsova S.A., Aleksandrova N.B., Kuznetsov B.N. Composition and transformation the main components autohydrolysed pine, spruce and aspen wood. Chemistry for Sustainable Development. 2001. Vol. 9(5). P. 655-665. (in Russ.)].

15. Sun M., Hong L. Impacts of the pendal functional groups of cellulose precursor on the generation of pore structures of activated carbons // Carbon. 2011. Vol. 49. P. 2173-2180.

16. Gao N., Li A., Quan C, Du L., Duan Y. TG-FTIR and Py-GC/MS analysis on pyrolysis and combustion of pine sawdust // J. Anal. Appl. Pyrolysis.2013. Vol. 100. P. 26-32. 